\title{
POLITENESS AND SELF-CENSORSHIP IN CHATROOM DISCOURSE
}

\author{
Jariah Mohd Jan, Gillian Ng Mei Ing and Ainun Rozana Mohd Zaid \\ University of Malaya
}

\begin{abstract}
In this borderless world, Internet has become an important tool of communication for teenagers. It provides the opportunity to interact with thousands of people from all over the world at any time. Focusing on the new medium of synchronous computer mediated communication; namely the MSN Instant Messenger, this study seeks to examine the language and social behavior of Malaysian teenagers. This paper also discusses the notion of self-censorship, which is frequently used by teenagers in this study as a strategy to preserve politeness and maintain solidarity amongst chatters.
\end{abstract}

KEY WORDS: POLITENESS, SELF-CENSORSHIP, CHATROOM DISCOURSE, PROFANITY, INTERNET LANGUAGE

\section{INTRODUCTION}

Human communication is a process involving interactive and collaborative effort and its success is dependent on the joint responsibility of all participants involved (Grice, 1975; Clark, 1996). However, over the years, communication has changed. There are many new and improved technologies where conversation is no longer exclusively a face-to-face act or a simple chat over the telephone (Haggerty, 2000). Nowadays, there are computers and the Internet. One common means of Internet communication is through chat groups such as MSN Instant Messenger. The chat room is the medium used for transferring messages between its users.

Today, as chat room talk grows in popularity, people from Malaysia, for example, can communicate with others from any parts of the world via the Internet. In public chat areas people use user names or nicknames to represent themselves. Due to the fact that chatting is an anonymous encounter, it is impossible to know anything about people on the Internet except what they choose to tell you.

In contemporary U.S. society, many adolescents spend considerable amounts of time in online interactions (Walsh, Wolak \& Mitchell, 2013; Subrahmanyam, Greenfield, Kraut, \& Gross, 2001). The language used on the Internet demonstrates an evolution of discourse (Crystal, 2001) and adolescents are found to be in the midst of that language evolution (Greenfield \& Subrahmanyam, 2003).

The language of the Internet entails both traditional linguistic forms, and adapted ones that include slang and non-standard forms that are sometimes used in offline life. In short, netspeak has become an emergent discourse that is shaped entirely by the creativity of its community (Crystal, 2001).

However, in face-to-face interaction, strangers rely initially on the cultural and sociological levels of information to form and cast impressions, then move toward the psychological level (Miller \& Steinberg, 1975). Through Computer Mediated Communication (CMC), social information can be 


\section{POLITENESS AND SELF-CENSORSHIP IN CHATROOM DISCOURSE}

exchanged to form and manage impressions and to develop relationships (Walther, 1992; 1993; 1996; Lea \& Spears, 1991; Reid, 1993; O'Sullivan, 2000). Paralinguistic cues, such as linguistic style, politeness strategies, name usage, and emoticons, also convey social information that influences impressions (Postmes, Spears \& Lea, 1998).

In public chat areas, people can be polite or impolite as they are not interacting face to face. The study of CMC, which refers to the process of using computers and other digital technologies to communicate, explores many of these issues. Scholars have actively explored how identity and language are manifested in online interactions. Past research in CMC environments such as chat rooms, newsgroups, and MUDs has revealed interesting trends in the way individual identity is presented, language is used, and interactions have transpired (Turkle, 1995; Herring, 2000; Crystal, 2001; Calvert, 2002; Greenfield \& Subrahmanyam, 2003; Ostman, Fried \& Verschueren, 2011). It includes the construction of online identity (Turkle, 1995; Calvert, 2002), dialogue and online interactions (Herring, 2000; Calvert, Mahler, Zehnder, Jenkins, \& Lee, 2003; Greenfield \& Subrahmanyam, 2003), and the impact of technology on child and adolescent development (Roberts, Foehr, Rideout, \& Brodie, 1999; Subrahmanyam, Greenfield, Kraut, \& Gross, 2001).

\section{STATEMENT OF THE PROBLEM}

Being online allows people to explore various facets of identity, especially ones that may be less comfortable in non-virtual worlds (Calvert, 2002). There are, however, issues on politeness being questioned. This includes language used by teenagers in portraying politeness as well as the use of profanity in communication.

Since it is found that teenagers spend a considerable amount of time in online interactions (Wilcox \& Stephen, 2013), many people have often wondered whether online communication has any effect on the level of politeness in interactions. As interaction is not a face-to-face contact, people have yet to find out whether chatters tend to chat crudely and interrupt abruptly or if chatters simply act politely to impress the other party who is chatting with them.

In online chat rooms, chatters usually do not know each other personally. Even then, at times they assume that they know the person whom they are chatting with and use inappropriate language like swear words, taboo topics, etc. regardless of gender. Previous studies have indicated that men tend to be more impolite and use coarser language compared to women (Lakoff, 1975; Holmes, 2013). The question which remains is whether there will be differences in the degree of politeness when the two genders communicate in online chat rooms. Will both gender talk politely? This online language continues to evolve and it remains an important area of study when considering the styles in which Internet users interact and construct their identity in online chat rooms.

The purpose of this study is to find out whether politeness is present in online chat room conversations through focusing on language used by teenagers. Particularly, this study investigates the strategies used in determining politeness and/or impoliteness. This research is thus important to create awareness to the public, especially parents and guardians, in providing a comprehensive picture of what is happening to the use of language in online chat rooms and how it might affect our daily interactions. 
POLITENESS AND SELF-CENSORSHIP IN CHATROOM DISCOURSE

\section{Computer Mediated Communication (CMC)}

Communication in face-to-face interaction has been defined as exchange of ideas or information between two or more individuals (Kaul, 1988). Communication is usually linked to oral language and face-to-face communication, with the only exception being telephone conversations. According to Noblia (1998), computer mediated communication (CMC) provides a link between oral and written communication, which produces a categorical change, affecting not only the notion of what the conversation is, but the speaking-writing dichotomy as well.

Today, CMC is being used as a convenient measure to construct a new type of social interaction beyond space barriers. $\mathrm{CMC}$ has become an important means of communication in most organizations, and has changed the structure of communication channels at the workplace, making emails and Internet the most commonly used mediums of communication (Jaffe et al., 1995). Emails and mobile text messages are the most recent in a long line of alternatives to face-to-face communication and are rapidly replacing the personal, hand-written letters of the nineteenth century and the telephone calls of the twentieth-century as the premier form of communication in the twenty-first century (NUA Internet Surveys, 1998).

One of the definitive features of the Internet is the language used within its community- a representation of creative and innovative adaptation by users. Similarly, the language used on the Internet demonstrates an evolution of discourse (Crystal, 2001). As these applications are increasing in both depth and range, so is the case for the growth of online chat room and discussion groups. Crystal defines chat room as a multi-party electronic discourse. The conversations in chat rooms are in real-time, continuous or on-going, and are usually focused on one particular subject matter. As the name of the channel suggests, users of chat rooms think of them as being very similar to real-life chat; as a matter of fact, chat participants have the general expectation that the language in chat rooms should have the features of a real-life chat.

Crystal (2001:28) asserts, "what makes netspeak so interesting as a form of communication is the way it relies on characteristics belonging to both sides of the speech/writing divide". He also indicates that the situations of e-mail chat groups and virtual worlds, though expressed through the medium of writing, display several of the core properties of speech. They are time-governed, expecting or demanding an immediate response; they are transient, in the sense that messages may be deleted (as in e-mails) or be lost to attention as they scroll off the screen (as in chat groups); and their utterances display much of the urgency and energetic force which is characteristic of face-toface conversation. The situations are not all equally 'spoken' in character. We 'write' e-mails not 'speak' them (Crystal, 2001:29). But chat groups are for 'chatting' and people certainly 'speak' to each other there.

The language of the Internet continues to evolve with the communities that participate in its discourse, an idea that is reflected in Chomsky's (1999) belief that the knowledge of language grows within its speech community, including language use, pronunciation and interpretation.

\section{Teenagers in CMC}

Many adolescents today cannot remember a time when the Internet was not a part of their world: at school or at home, for homework or for recreation. One part of that world includes synchronous on-line discussions, popularly known as Chat rooms. 
The teenage years are fraught with questions: Who am I? What kind of person do I want to be? What do I want to do with my life? What kind of relationships do I want? The Internet offers opportunities for adolescents to satisfy that need to express, explore, and experiment with their identities (Umarani \& Kumar, 2013). Through the use of Internet, adolescents explore their identities. They experiment intensely with new intimate relationships. They look for groups where they can feel a sense of belonging. The Internet offers an almost limitless array of people and groups to explore - all kinds of people and groups with all kinds of personalities, backgrounds, values, and interests (Suler, 1998).

\section{Politeness and CMC}

Politeness is, undoubtedly, the central part of every single human interaction and social relationship. Regardless of the kind of function we carry out in language or in communication, there always exists an element of politeness. A greeting to somebody in the street, for instance, offers us a range of expressions to be used, such as "good morning" or "hi", and we are inevitably taking part in some aspects of politeness. Defined by The Concise Oxford Dictionary (1995) as the courteous manner that respects accepted social usage, politeness is present in all the existing societies in the world whenever communication takes place. Human beings communicate with each other when they interact as social being.

According to Porter (1913), politeness is best expressed as the practical application of good manners or etiquette. It is a culturally defined phenomenon, and what is considered polite in one culture can often be perceived as being rude or simply strange in another. While the goal of politeness is to make all of the parties feel at ease and civil with one another, these culturally defined standards at times may be manipulated to inflict shame on a designated party (ibid.).

According to Nofsinger (1990), everyone can conduct ordinary conversation - or so it seems. The immense power of everyday talk is at our disposal. We can contact and influence other people: to enlist their help, to offer them companionship, to protect ourselves from their demands, to establish important relationships with them, and to present ourselves as having the qualities that we admire (ibid.:1). Almost everything we do that concerns other people involves us in conversation. Unfortunately, at times, we experience problems during conversation that threaten to embarrass us or prevent us from reaching our immediate and long-term goals.

Brown and Levinson (1978), Jamaliah Mohd Ali (1995b), and Jariah Mohd Jan (1999) demonstrate that despite the fact that people follow face-wants and abide by social rules in their daily face-toface interactions to maintain stability in societies, they still display the use of vulgarity (profane language) in their language to vent or display their anger. Profanity means adopting language which is vulgar in nature and consists of curses and swear words, and is seen as culturally offensive. Other words commonly used to describe profane language or its use include curse, derogatory language, swearing, oath, bad word, dirty word, strong language, obscene language, and blasphemous language (religious profanity). The issue on profanity will be further discussed in the next sections.

In almost every culture, people usually try to avoid using strong swear words in their daily conversations. However, in today's society, due to the influence of modern technology and exposure to more developed countries around the world, swearing has been seen to assimilate into the Malaysian culture. The use of swear words is seen as language abuse and a form of impoliteness in most cultures. Impoliteness means lacking good manners, such as being 


\section{POLITENESS AND SELF-CENSORSHIP IN CHATROOM DISCOURSE}

discourteous, disrespectful, ill-bred, ill-mannered, rude, uncivil, ungracious, unmannerly, unpolished whilst being rude, rough, crude and raw are seen as lacking in social refinement.

Politeness is one common means through which gender is cued in asynchronous CMC. Predominantly female groups may have more and more strictly enforced posting rules designed to ensure the maintenance of a civil environment (Herring, 1996a). In contrast, men generally appear to be less concerned with politeness. They issue bold face-threatening acts such as criticisms and insults, violate online rules of conduct, tolerate or even enjoy 'flaming' and tend to be more concerned about threats to freedom of expression than with attending to others' social face (Herring, 1994:292). These patterns have been noted even in gay and lesbian discussion groups and among women who have succeeded in traditionally male-dominated professions such as computer science (Herring, 1995). Inappropriate or contentious messages can 'give away' individuals who are attempting to pass as the opposite gender in Internet discussion groups (Herring, 1996a: 486).

O'Sullivan and Flanagin (2003) observe the use of 'flaming' in online communication. Typical descriptions represent flaming rude or insulting using "nasty and often profane diatribe" (Chapman, 1995:14). It is derogatory, obscene or inappropriate language (Seabrook, 1994). Flaming is also similarly described as "the hostile expression of strong emotions and feelings" (Lea et al., 1992:92). However, others characterize flaming in more abstract terms. Thus, flaming is regarded as antisocial interaction and for it is a form of social aggression (Colomb and Simutis, 1996).

Finally, cooperation can be achieved by using politeness markers and indicators, such as hedges, superpolite forms, avoidance of flaming in CMC and the use of self-censorship. Self- censorship acts as a swear filter or profanity filter to swap out a list of inappropriate words and phrases with a variety of alternatives by the chatter himself/herself. Alternatives can include a sequence of shift-number characters, such as!@ $\$ \$ \%^{\wedge} \&^{*}$, white space (nothing at all) or by using asterisks $\left(^{*}\right)$ of either a set length, or the length of the original word being filtered.

Although there is a sense of anonymity in online conversation, which can lead to an expression of impoliteness or hostility, these expressions are communicatively essential and important in the study of chat room discourse. The use of self-censorship will be further discussed in the following sections.

\section{METHODOLOGY}

Data collection was done based on a focused yet convenient sampling within a small group of teenagers, who are also school friends, comprising of teenage boys (10) and girls (10) between 15 and 18 years old. This sample will be the researcher's defined population as a representative of the teenage population.

In order to gain an insight into politeness in chat room conversation, a total of 133 minutes of chat scripts was collected over a period of five days from a private web-based chat room namely MSN Instant Messenger. The MSN Instant Messenger is a web browser where one is allowed to talk online and in real-time with friends and family. Each participant enters using an individual e-mail address and password. Once one has logged in, one is allowed to add new friends into the 


\section{POLITENESS AND SELF-CENSORSHIP IN CHATROOM DISCOURSE}

discussed instrument. Those who are online will be alerted when members log in to the chat room and this allows one friend to chat with another friend or a group of them.

This study employs a qualitative approach in order to describe the use of language in chat rooms. Qualitative data cannot be placed into a context that can be graphed or displayed as a mathematical term. With this in mind, and having been given consent by the participants of the chat room, the researchers gathered and analyzed the chat scripts to find out whether there are regular or similar patterns employed by chatters during their discussions. Chat scripts which were too short and those lacking information with regards to politeness were excluded. The identification and interpretation followed the selection of scripts.

In order to collect the data for the study, the researcher had to enter the chat room as an observer. This was done by logging in on the MSN Instant Messenger that is linked to the Internet. In this case, the researcher was given permission and consent by all the participants before being invited to enter the MSN private chat room to observe and collect the chat scripts. Due to the fact that this is not a public chat room, getting permission to collect the chat scripts is important as to respect chatters' privacy. The collected chat scripts were then noted for the date and time of talk.

From the data gathered, the analysis is made using Conversation Analysis (CA) as it gives the researcher more opportunity to explore in detail every line of the chat scripts. CA not only aims to identify the principles that enable individuals to negotiate and exchange meaning, but also allows an in depth analysis of data, which enables the researcher to focus on the relationship between conversation and language. The central question addressed by CA is how conversations work. It involves a series of moves, turns, goals and strategies, which requires line-by-line analysis of the chat scripts. CA also enables the researcher to explore the linguistic cues which take place in the conversations.

\section{ANALYSIS OF DATA AND FINDINGS}

The analysis of data reveals that politeness is present through the use of self-censorship although profane language appears to be profound.

\section{Profane Language}

In almost every culture, people try to avoid the use of strong swear words in their daily conversations. However, in today's society, due to the influence of the western world, swearing has been assimilated into our Malaysian culture and is becoming rampant. It is seen as language abuse and it is disturbing to see that it appears in teenagers' speech.

From the findings, teenagers are shown to practice vulgarity in their speech in the chat room.

\section{$\underline{\text { Extract A }}$}

$\begin{array}{lll}\text { 33. } & \text { Oh Canada!: } & \text { pass up tomorrow right? or something? } \\ \text { 34. blank-ed: } & \text { hah?? } \\ \text { 35. blank-ed: } & \text { what the hell } \\ \text { 36. } & \text { blank-ed: } & \text { no lar }\end{array}$




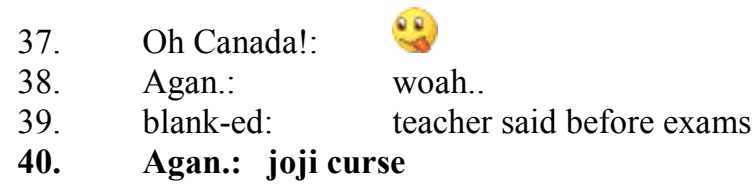

In Extract A, blank-ed in line 35 swears when he finds out that he needs to hand in his homework the next day at school. He cursed and denied the need to hand in his homework that soon as he was not ready to do so. This sample shows that teenagers cursed when being disappointed and when things go beyond their expectation. The use of profanity is considered ill-mannered in most societies and is therefore not accepted. blank-ed's friend in line 40 (Agan) disapproves of his friend's behavior and brings up the issue of blank-ed's curse. More evidence of displayed profanity by teenagers is shown in Extract B (line 263).

\section{$\underline{\text { Extract B }}$}

258. Oh Canada!: you all psyched out about the exams?

259. blank-ed: ahahahh

260. Oh Canada!: Bluek

261. Agan.: woo

262. Agan.: they really crept up on me this time

263. Carcererius: no shit, i've done failed my upsr

264. Oh Canada!: how so?

265. Carcererius: and i'm gonna fail my pmr too

266. Carcererius: and half of my spm papers

267. blank-ed: owh yea sure

268. Carcererius: and flunk all my stpm papers

In Extract B, Carcererius curses because he is worried about the exams (PMR, UPSR, SPM and STPM are Malaysian Public Examinations). Apparently, he has failed his exam before and it is a serious matter. He seems confident that he might also fail for the coming one. Carcererius swore because he felt frustrated with his performance in school. Swearing is not advisable in most societies although one is frustrated as one ought to learn how to express one's frustrations.

One can also be seen as disrespecting oneself as shown in the following extract. Line 694 in Extract $\mathrm{C}$ displays how wolfie the fox is not ashamed of his act of cursing. He curses about himself and is very casual about it too. His use of vulgarity is very impolite and unacceptable to any hearer.

\section{$\underline{\text { Extract C }}$}

$\begin{array}{lll}\text { 690. } & \text { wolfie the fox: } & \text { if you cant handle me } \\ \text { 691. } & \text { wolfie the fox: } & \text { hahahha } \\ \text { 692. } & \sim \text { DĂN1ĕl : } & \text { dude } \\ \text { 693. } & \text { handydandy: } & \text { owh.. }\end{array}$

694. wolfie the fox: and im the weakest son of a bitch 


\section{POLITENESS AND SELF-CENSORSHIP IN CHATROOM DISCOURSE}

Throughout the analysis, there are many instances whereby participants use blasphemous language. Profanities may often cause offense in most contexts, especially if they have a religious meaning. Saying God's name (or an identifier such as Lord or God) in vain for instance, is regarded as impolite. However, in today's society, not many people realize that the expressions of phrases like "oh my god" or "omg" is similar to using a profane language. In Extract D, blasphemous language is uttered twice (lines 1036 and 1041) by the chatters, in the manner of repeating each other's utterances. This is deemed improper by respectable society at large and is offensive regardless of gender.

\section{$\underline{\text { Extract D }}$}

$\begin{array}{lll}\text { 1036. } & \text { Aizat Amzar: } & \text { omg! } \\ \text { 1037. } & \text { Captain Ragetti-Hedwig: } & \text { haaaaaaaaaaaaaahaaaaaaaaaaaaaaaa } \\ \text { 1038. } & \text { Aizat Amzar: } & \text { change topic } \\ \text { 1039. } & \text { Aizat Amzar: } & \text { please } \\ \text { 1040. } & \text { Captain Ragetti-Hedwig: } & \text { ahahahahhhahaha } \\ \text { 1041. } & \text { Captain Ragetti-Hedwig: } & \text { omg it is! }\end{array}$

\section{Self-Censorship}

Self-censorship in language is the suppression of speech or deletion of communicative material which may be considered objectionable, harmful or sensitive. It is the means by which any material that is of questionable morality is removed. The data reveal that teenagers also do practice avoidance of strong swear words in chat room conversations. It is done by self-censoring where asterisks, acronyms, sound replication and incompletion strategy are used in replace of vulgar words.

In Extract E, wolfie the fox (line 707), shows that he is tempted to curse but decides to use asterisks instead. This is viewed as a way of self-censorship and is considered as a display of politeness. Although the chatter has the intention of being impolite, he self-censored himself as not to offend the 'listener'. In this way, he is able to maintain solidarity as frequent use of swearing may discourage other chatters to continue chatting with him or those who frequently conduct themselves in rude manner in the chat room.

\section{$\underline{\text { Extract E }}$}

706.

DĂN1ĕl :

ok nitez piggi

\section{wicked hot son of a}

Apart from use of asterisks, incorporating acronyms is another form of self-censorship displayed by Aizat Amzar in line 922 in the example extract. This act is perceived as polite and by doing so, he has avoided the use of profane language and being despised by other chatters. 


\section{POLITENESS AND SELF-CENSORSHIP IN CHATROOM DISCOURSE}

\section{Extract $\mathrm{F}$}

921. Captain Ragetti-Hedwig: what laaaaaaaaaaaaaaaa

922. Aizat Amzar: wth

923 Captain Ragetti-Hedwig: alang alang why not make up a whole pentagon of me gchan brendan edward and agan

924 Captain Ragetti-Hedwig: CHIIIIIIIIIISSSSSSSSSSSSSSSSSSSSSSSS

925 Aizat Amzar: ya lah!

Extract G shows how $\sim \mathrm{DA} N 1$ ĕl uses sound replication to censor his intended strong language. $\sim$ DĂN1ĕl 's effort to substitute the strong language with sound replication makes his ill intention to swear less questionable.

\section{Extract G}

$\begin{array}{lll}\text { 425. } & \sim \text { DĂN1ĕl : } & \text { btw } \\ \text { 426. } & \text { wolfie the fox: } & \text { she already here? } \\ \text { 427. } & \sim \text { DĂN1ĕl : } & \text { "toot* } \\ \text { 428. } & \sim \text { DĂN1ĕl : } & \text { wat u mean by shes there? } \\ \text { 429. } & \text { wolfie the fox: } & \text { i mean } \\ \text { 430. } & \text { wolfie the fox: } & \text { she already here? }\end{array}$

Extract H sees Aizat Amzar adopting sound replication to self-censor a bad word. It is considered as appropriate and use of less offensive language.

\section{Extract $\mathrm{H}$}

\begin{tabular}{|c|c|c|c|}
\hline 1074. & Aizat Amzar: & & dun worry \\
\hline 1075. & Aizat Amzar: & & haha \\
\hline 1076. & Aizat Amzar: & & zahir is a \\
\hline $\begin{array}{l}1077 . \\
1078\end{array}$ & $\begin{array}{l}\text { Aizat Amzar: } \\
\text { Cantain Ragetti-Hedwio. }\end{array}$ & tuttt & \\
\hline
\end{tabular}

Extracts I and J show instances whereby teenagers employ incompletion strategy when they curse and swear. It is obvious that these teenagers have the intention to swear out loud but are able to control in avoiding the use of taboo language. Instead of finishing the entire phrase with the intended swear word, they efficiently adopt incompletion strategy by leaving it as incomplete to appear subtle in the eyes of other chatters.

\section{Extract I}

299. blank-ed: hey....anyone goin for planetshakers?!

300. Carcererius: so much for studying

301. Oh Canada!: what the..

302. Oh Canada!: where are they from anyway?! 


\section{$\underline{\text { Extract J }}$}

$\begin{array}{lll}\text { 1346. } & \text { Jeremy: } & \text { secret ya! } \\ \text { 1347. } & \text { Jeremy: } & \text { only u and i } \\ \text { 1348. } & \text { DÁN1ĕl }: & \text { wat the }\end{array}$

The analysis suggests that by employing self-censorship strategy, chatters are able to maintain solidarity and seem more respectable when using less offensive language. Chatters are also aware that they could be judged by their use of what is deemed to be proper or improper language in chat rooms. In addition, since the sample groups in which the data collected are school friends, the decision to be more or less polite may have been influenced by their level of familiarity and social distance. However, choosing to be polite will be an advantage and thus preserves friendship and solidarity.

\section{CONCLUSION}

The data reveal that teenagers are drawn to the use of profane language in their conversations due to the following circumstances:

- Occurrence of unexpected situations,

- Denial of a fact or statement,

- Feeling of disappointment, concern, frustration or anger regarding issues,

- Description of own or other's weaknesses, and

- Use of empty adjectives for fun.

The circumstances given infer ill-mannered behavior which is deemed improper and unacceptable by the society. It represents impoliteness in this study. Due to the fact that profane language is offensive, chatters are discouraged to employ its usage at all times. As mentioned earlier, chatters ought to keep language standards high because people in general form opinions about others (Walther, 1992; 1993; 1996; Lea \& Spears, 1991; Reid, 1993; O'Sullivan, 2000). Their use of language, be it proper or improper, influences an individual's perception of others if one is observed to continually exhibit the use of vulgarity. At the same time, such impolite use of language makes it difficult to maintain the level of solidarity among its chatters because the use of profanity promotes socially undesirable behavior, as it automatically creates negative effect on people's perception and belief.

However, by adopting self-censorship and filtering of profane words, the level of impoliteness changes. In daily conversations, it is unavoidable that people may sometimes use profane language but in order to sound less vulgar and offensive, they may opt to censor the abusive language.

In the Malaysian chat room under study, the use of profane language is seen to be more common. Nonetheless, chatters in the chat room sometimes do censor their language in various ways. In public chat sites, chatters usually chat in the presence of a moderator. A moderator controls and observes chatting behavior. If a chatter behaves impolitely or says what is perceived as inappropriate, the moderator has the right to ban the offender from entering the chat room if he/she creates an uncomfortable situation with explicit profane language to other chatters. 


\section{POLITENESS AND SELF-CENSORSHIP IN CHATROOM DISCOURSE}

As this study was conducted in a private chat room (MSN Instant Messenger) and not a public one, censorship is done by self-censoring the use of vulgarity using asterisks, acronyms, sound replication and incompletion strategy. Although not actually uttering the phrases out might be deemed as polite, this action of having the intention to use vulgar language is still perceived as improper and thus, regarded as impolite. Self-censorship strategy, which has been employed by some of the respondents in this study, is a reflection of politeness strategy.

\section{Summary}

The Internet has provided a new context for linguistic and non-linguistic exploration. Language on the Internet represents a new type of discourse that is shaped by the creativity and innovation of its communities of users (Crystal, 2001). This emerging pattern can then be used to express the identities of its adolescent users. Furthermore, politeness can only be seen once the identities of these users have been formed and the physical absence of the sender and receiver will further enhance the display of politeness among teenagers in the chat room.

However, the teenagers' use of profane language should also be taken into consideration and selfcensorship strategy ought to be encouraged as to avoid the display of impoliteness. In this sense, self-censorship enhances politeness (as seen in data findings) and at the same time helps teenagers to gain respect of others through abiding by the social rules (Jamaliah Mohd Ali, 1995b).

This study confirms that language in chat rooms is about developing closer rapport amongst chatters, hence, contributing to politeness regardless of gender. The research defines the distinctive features of chat room language and the existence of politeness even amongst teenagers in chat room discourse. Unlike other types of discourse, there is a need for chat room users to be aware of the embedded meanings behind the use of profane language and self-censorship. In short, this ability is crucial as it is the yardstick for those concerned to determine the level of politeness amongst teenagers in chat room discourse.

\section{REFERENCES}

Brown, P., \& Levinson, S. (1978). Universals in Language Usage: Politeness Phenomena. In E. Goody (ed.), Questions and Politeness: Strategies in Social Interaction, Cambridge: Cambridge University Press, 56-311.

Calvert, S. L. (2002). Identity Construction on the Internet. In S. L. Calvert, A. B. Jordan \& R. R. Cocking (Eds.), Children in the Digital Age: Influences of Electronic Media on Development, Westport: Connecticut: Praeger, 57-70.

Calvert, S. L., Mahler, B. A., Zehnder, S. M., Jenkins, A., \& Lee, M. S. (2003). Gender Differences in Preadolescent Children's Online Interactions: Symbolic Modes of SelfPresentation and Self-Expression. Applied Developmental Psychology, 10(2), 81-118.

Chapman, G. (1995). Flamers. The New Republic, 212, 13-15. 


\section{POLITENESS AND SELF-CENSORSHIP IN CHATROOM DISCOURSE}

Clark, H. H. (1996). Using Language. Cambridge: Cambridge University Press.

Colomb, G. C., \& Simutis, J. A. (1996). Visible Conversation and Academic Inquiry: CMC in a Cultural Diverse Classroom. In S. C. Herring (Ed.), Computer Mediated Communication: Linguistic, Social and Cross-Cultural Perspectives, Amsterdam: J. Benjamins, 203-222.

Crystal, D. (2001). Language and the Internet. Cambridge: Cambridge University Press

Greenfield, P. M., \& Subrahmanyam, K. (2003). Online Discourse in a Teen Chatroom: New Codes and New Modes of Coherence in a Visual Medium. Journal of Applied Developmental Psychology, 24, 713-738.

Grice, H. P. (1975). Logic and Conversation. In P. Cole \& J. Morgan (Eds.), Syntax and Semantics, Vol 3, New York: Academic Press, 41-58.

Haggerty, K. (2000). Conversation Analysis: A Study of On-line Chatrooms vs. Oral Communication. Unpublished Thesis. Western Connecticut State University. Retrieved on August 28, 2007 from http://people.wcsu.edu/mccarneyh/acad/HaggertyThesis.html

Herring, S. C. (1994). Politeness in Computer Culture: Why Women Thank and Men Flame. In Cultural Performances: Proceedings of the Third Berkeley Women and Language Conference, 278-294. Berkeley Women and Language Group. Retrieved on December 22, 2007 from http://ella.slis.indiana.edu/ herring/politeness.1994.pdf

Herring, S. C. (1995). Men's Language on the Internet. Proceedings of the 2nd Nordic Language and Gender Conference. Retrieved on December 22, 2007 from http://ella.slis.indiana.edu/ herring/men.1995.pdf

Herring, S. C. (1996a). Computer-Mediated Communication: Linguistic, Social and Cross Cultural Perspectives. Amsterdam: Benjamins.

Herring, S. C. (2000). Gender Differences in CMC: Findings and Implications. Computer Professionals for Social Responsibility Journal, 18(1).

Holmes, J. (2013). An Introduction to Sociolinguistics $\left(4^{\text {th }}\right.$ Ed). London: Longman.

Jaffe, J. M., Lee, Y. E., Huang, L. N., \& Oshagan, H. (1995). Gender, Pseudonyms, and CMC: Masking Identities and Baring Souls. Paper presented at the 45th Annual Conference of the International Communication Association, Albuquerque, New Mexico. Retrieved on December 22, 2007 from http://research.haifa.ac.il/ jmjaffe/genderpseudocmc/

Jamaliah Mohd Ali. (1995b). Malaysian Student Seminar: A Study of Pragmatic Featuresin Verbal Interaction. Unpublished Ph.D Thesis. University of Malaya, Kuala Lumpur.

Jariah Mohd Jan (1999). Malaysian Talk Shows: A Study of Power and Solidarity in Inter-Gender Verbal Interaction. Unpublished Ph.D Thesis. University of Malaya, Kuala Lumpur.

Kaul, A. (1988). Business Communication. New Delhi: Prentice Hall of India.

Lakoff, R. (1975). Language and Woman's Place. New York: Harper and Row. 


\section{POLITENESS AND SELF-CENSORSHIP IN CHATROOM DISCOURSE}

Lea, M., \& Spears, R. (1991). Computer-Mediated Communication, Deindividuation and Group Decision-Making. International Journal of Man-Machine Studies, 23, 283- 301.

Lea, M., O'Shea T., Fung, P., \& Spears, R. (1992). 'Flaming' in Computer-Mediated Communication: Observations, Explanations, Implications. In M. Lea (Ed.), Contexts of Computer Mediated Communication (pp. 89-112). New York: Harvester Wheatsheaf.

Miller, G. R., \& Steinberg, M. (1975). Between People: A New Analysis of Interpersonal Communication. Chicago: Science Research Associates.

Noblia, M. V. (1998). Computer-Mediated Communication: A New Way of Understanding the Language. International Conference: 25-27 March 1998, Bristol, UK. Retrieved on November 15, 2007 from http://web.mit.edu/ hartman/public/portfolio/researchpaper.pdf

Nofsinger, R. E. (1990). Everyday Conversation: Interpersonal Commtexts 1. CA: Sage Publications, Inc.

NUA Internet Surveys. (1998). Retrieved on November $1^{\text {st }}, 1997$ from http://www.nua.ie/how_many_online/index.html

Östman, M., Fried, J. O. \& Verschueren, J. (eds.). (2011). Variation and Change. Pragmatic perspectives. John Benjamin Pub. Co.

O'Sullivan, P. B. (2000). What You Don't Know Won't Hurt ME: Impression Management Functions of Communication Channels in Relationships. Human Communication Research, 26, 403-431.

O'Sullivan, P. B., \& Flanagin, A. (2003). Reconceptualizing "Flaming" and Other Problematic Communication. New Media and Society 5(1), 69-94.

Porter, N. (1913). Webster's Revised Unabridged Dictionary. Published by G \& C. Merriam Co.

Postmes, T., Spears, R., \& Lea, M. (1998). Breaching or Building Social Boundaries? SIDE Effects of Computer-Mediated Communication. Communication Research, 25, 689-715.

Reid, E. (1993). Social Issues on Internet Relay Chat. Media Information Australia, 67, 62-70.

Roberts, D. F., Foehr, U. G., Rideout, V. J., \& Brodie, M. (1999). Kids and Media at the New Millennium. Menlo Park, CA: The Henry J. Kaiser Family Foundation.

Seabrook, J. (1994). My First Flame. The New Yorker, 70, 70-99.

Subrahmanyam, K., Greenfield, P., Kraut, R., \& Gross, E. (2001). The Impact ofComputer Use on Children's and Adolescents' Development. Journal of Applied Developmental Psychology, 22, 7-30.

Suler, J. (1998). Adolescents in Cyberspace: The Good, The Bad, and The Ugly. In J. Suler (ed.), Psychology of Cyberspace. Retreived on August 28, 2007 from http://www.rider.edu/users/suler/psycyber/adoles.html 


\section{POLITENESS AND SELF-CENSORSHIP IN CHATROOM DISCOURSE}

Thomson, D. (1995). The Concise Oxford Dictionary of Current English. Nineth Edition. New York: Oxford University Press.

Turkle, S. (1995). Life on The Screen. New York: Simon and Schuster.

Umarani, P. \& Kumar, A. (2013). Social media and mobile internet usage among teenagers and young adults: an exploratory study. International Journal of Logistics and Supply Change Management Perspectives. Vol 2, No. 4, 547-551.

Walsh, W. A., Wolak, J., \& Mitchell, K. J. (2013). Close relationships with people met online in a national U.S. sample of adolescents. Cyberpsychology: Journal of Psychosocial Research on Cyberspace, $\quad 7(3), \quad$ Article 1. http://cyberpsychology.eu/view.php? cisloclanku=2013112801\&article=4

Walther, J. B. (1992). Interpersonal Effects in Computer-Mediated Interaction: A Relational Perspective. Communication Research, 19(1), 52-90.

Walther, J. B. (1993). Impression Development in Computer-Mediated Interaction. Western Journal of Communication, 57, 381-398.

Walther, J. B. (1996). Computer-Mediated Communication: Impersonal, Interpersonal, and Hyperpersonal Interaction. Communication Research, 23, 3-43.

Wilcox, K. \& A. T. Stephen. (2013). Are close friends the enemy? Online social networks, selfesteem, and self-control. Journal of Consumer Research, Vol. 40, 90-103. 